\title{
El porvenir de la formación docente universitaria: Entre tensiones y alternativas
}

\author{
Silvia Morelli \\ María Verónica Zamudio \\ (Escuela de Ciencias de la Educación) \\ (Universidad Nacional de Rosario. Argentina)
}

El 15 y 16 de octubre de 2009 en la Facultad de Humanidades y Artes de la UNR, se realizaron las "II Jornadas de Formación Docente Universitaria: El porvenir de la Formación Docente Universitaria: entre tensiones y alternativas", organizadas por la Escuela de Ciencias de la Educación. Actividades académicas, propias de eventos de este tipo, se dieron lugar para instalar debates en torno a la formación docente en las universidades. Heredera de las Jornadas "La Formación Docente Universitaria en la encrucijada: Una cuestión de políticas y prácticas", desarrolladas en 2008, supo abrirse al desafío de realizar una convocatoria a nivel nacional, invitando a otras universidades a reflexionar sobre la formación docente en momentos en los que ocupa un lugar destacado en la agenda educativa.

Organizadas en torno a problemáticas específicas, sus reflexiones se vuelven recurrentes para ser tratadas, durante dos largos y productivos días, una y otra vez, por diferentes sujetos en diferentes espacios. Fue así como el debate se sostuvo en derredor de la formación docente y las tecnologías digitales, las instancias de formación, la relación entre la didáctica y las didácticas específicas, las investigaciones sobre prácticas institucionales, la tensión entre competencias y saberes y las condiciones materiales de trabajo docente en las universidades. Paneles, conferencias, sesiones de ponencias y pósters, presentaciones de libros, se ofrecieron como espacios donde el debate se hizo posible haciendo aflorar pasiones intelectuales y preocupaciones prácticas.

Andrea Alliaud, en la conferencia de apertura se refiere al oficio de enseñar, a cómo transmitir los saberes de la docencia, a producir su arte- 
sanía, a mirar desde otro ángulo el oficio, a hacer un pasaje de secretos, gajes, experiencias. Descubrir las obras maestras y crear cultura para nuevas obras. Mientras que María Laura Méndez, en la conferencia de cierre, enfatizó sobre el estado actual de la formación docente y la ubicación del problema en los jóvenes estudiantes de la formación docente que educarán jóvenes. Sin olvidarse del escenario socio-cultural posmoderno y de las luchas por zafar de las huellas del neoliberalismo, ofrece intersticios para repensar la formación docente con ética y creatividad.

Las sesiones de ponencias arrojaron múltiples encuentros en torno a diferentes temáticas y grupos de profesores-investigadores no sólo proveniente de la universidad anfitriona, sino también de la Universidad Nacional de Tres de Febrero, Universidad Nacional del Nordeste, Universidad Nacional de San Luis, Universidad del Museo Social Argentino, Universidad Nacional General Sarmiento, Universidad Nacional de la Plata, Universidad de Buenos Aires, Universidad Tecnológica Nacional, Universidad Nacional de Entre Ríos, Universidad Nacional de Catamarca, Universidad Nacional de Córdoba, Universidad Nacional de La Matanza, Universidad Católica de Córdoba, Universidad Nacional de Misiones, Universidad Nacional de Lanús, Universidad Nacional del Sur, Universidad Nacional de Salta, Universidad Nacional de la Pampa, Universidad Nacional del Litoral, Universidad Nacional de Tucumán, Institutos de Enseñanza Superior y CONICET. Estas sesiones estuvieron coordinadas por Elisa Petrone, María Inés González, Elvira Scalona, Ana María Hernández, Norma Placci, Elisa Welti, Natalia Fattore, Silvana Galetto, Patricia Abbonizio y Natalia Sgreccia, quienes desde la protohistoria de cada sesión, cuando se modeló el abstract, intercambiaron opiniones y reflexiones con los distintos autores. La puesta en escena de las ponencias no fue más que un paraje en ese camino.

Dos libros condecoran el trabajo de equipos de investigación de la Escuela de Ciencias de la Educación y convirtieron a las II Jornadas en oportunidad para presentarlos. El primero de ellos "Los dispositivos para la formación en las prácticas profesionales”, de Homo Sapiens Ediciones, coordinado por Liliana Sanjurjo. Resulta del proyecto "La construcción del conocimiento profesional docente en los primeros procesos de socialización profesional. La inserción de los graduados docentes de la zona sur de la provincia de Santa Fe en las instituciones del medio" (1). Contó con tres de sus autoras en la presentación: Alicia Caporossi, Ana España y María Fernanda Foressi.

El segundo de los libros "Sobre viejos y nuevos saberes. Educación, trabajo y producción en la Provincia de Santa Fe" de Laborde Editor. Coordinado por Edgardo Ossanna, tuvo por presentadores a Enrique Barés, 
Luis Garcés y su coordinador. Este trabajo, resulta del Proyecto "Los procesos de enseñanza y aprendizaje de saberes socialmente productivos. Los saberes del trabajo" (2).

Los paneles configuraron variopintas escenas de debate convertidos en territorios de reflexión entre coordinadores, panelistas y asistentes. Se presentaron diferentes aportes sobre la didáctica y las epistemologías disciplinares, las tecnologías en proyectos de enseñanza, los saberes y las competencias y posicionamientos desde las asociaciones gremiales como COAD (3), AMSAFE (4) y AGCER (5).

Para los profesores comprometidos con las tareas de docencia; para los curiosos, atentos y expectantes; para los potenciales participantes de siguientes jornadas de formación docente, para aquellos que necesitan leer textos cuya trama ofrezca diferentes direcciones y lenguajes, los invitamos a consultar la página www.jornadas-unr-com.ar, a sumergirse en el CD ROM con las sesiones de ponencias, acceder a los resúmenes de las ponencias y pósters. Los invitamos a construir redes que tejan contornos sociales sobre el compromiso inalterable de las universidades con su propia formación docente.

\section{Notas Bibliográficas}

(1) Proyecto de Investigación Científica y Tecnológica Orientado al conocimiento del Sistema Educativo Nacional (PICTO 2005) en el que participan la cátedra de Residencia Docente de la Carrera de Ciencias de la Educación (UNR) y 14 Institutos de Formación Docente del Sur del Santa Fe. Este proyecto estuvo dirigido por Liliana Sanjurjo y participaron Alicia Caporossi, Ana España, Ana María Hernández, Iris Alfonso y María Fernanda Foressi.

(2) Este proyecto fue dirigido por Adriana Puiggrós, seleccionado por la Agencia Nacional de Promoción Científica y Tecnológica (FONCyT) como Programa de Áreas de Vacancia (PAV, 2003) en el rubro Educación. En el mismo intervienen investigadores de las Universidades Nacionales de Santa Cruz, Buenos Aires, San Juan y Rosario. El libro corresponde al subproyecto: "De la expansión cerealera a la desindustrialización: saberes socialmente productivos y ciclos económicos en Santa Fe en el siglo XX", que lleva por responsable a Edgardo Ossanna y a Mirta Moscatelli, Alberto Pérez, Gaspar Tomino, María del Carmen Fernández, Elisa Welti y María Eugenia Guida, como integrantes.

(3) Asociación Gremial de Profesores e Investigadores de la UNR.

(4) Asociación de Magisterio de Santa Fe.

(5) Asociación de Graduados en Ciencias de la Educación de Rosario. 